\title{
ROADMASTER ROADING CONTRACTORS CASE STUDY
}

\author{
Hazel Taylor \\ The Waikato Polytechnic, Hamilton, New Zealand \\ ithät@itwp.ac.nż
}

\begin{abstract}
Systems analysis students seldom experience the practical difficulties of the initial investigation into a client's requirements. They get little chance to practice the skills they need to investigate complex and confused problem situations, or to appreciate the wider organisational issues that can impact on a situation. This teaching case is designed to give students the opportunity to practice and apply investigation skills and to challenge them to consider the wider work environment when considering possible solutions to a problem situation. The case is conducted as a role-play, with students acting as systems analysts and teaching staff role-playing the clients. The students develop a report analyzing the client's situation based on the issues that arise during the interviews. Feed-back sessions focus on discussing how well the students applied various interviewing strategies previously covered in lectures, and on the wider organizational problems that could impact proposed information system solutions.
\end{abstract}

Keywords: IS education, case study, information requirements determination activities, information requirements determination issues, interviewing, organizational environment.

\section{Introduction}

This case is used in a third year undergraduate degree course on systems development, analysis and design. It is based on the author's experience as a consultant with the firm. Names have been changed to preserve confidentiality. The case illustrates the situations many software consultants face when working with small firms. They need to assess an organization's requirements in order to determine what assistance, if any, the software consultants can offer the organization. The organization's situation is often more complex than appears on the surface and even in small firms, personalities and politics can impact the initial analysis and ultimately the success of any implementation. The consultant's initial assessment generally cannot be charged to the client so there is a tension between the consultant's need to gather the necessary information as quickly as possible while at the same time ensuring that the assessment goes into enough depth to make an informed decision.

Material published as part of this journal, either on-line or in print, is copyrighted by the publisher of Informing Science. Permission to make digital or paper copy of part or all of these works for personal or classroom use is granted without fee provided that the copies are not made or distributed for profit or commercial advantage AND that copies 1) bear this notice in full and 2) give the full citation on the first page. It is permissible to abstract these works so long as credit is given. To copy in all other cases or to republish or to post on a server or to redistribute to lists requires specific permission and payment of a fee. Contact Editor@inform.nu to request redistribution permission.
The case is conducted as a role-play with students acting as new employees of the software consulting and development firm, Software Unlimited. The instructor and teaching colleagues play the roles of three key interviewees from the client, a road construction-contracting firm, Roadmaster Ltd. The students' task is to use limited consultation time efficiently to analyze their client's situation. The problem situation is briefly outlined to them in a memo from their boss and a letter from the client. From this realistically vague introduction, they must inform themselves about the business they are investigating and plan the interviews they will conduct. Having carried out the interviews, the students must assess the situation, identify the problem areas and make recommendations about what can be done. Although there is a need for better information systems at Roadmaster, solving the problems with the current system will not immediately result in improved performance. Students need to identify that other factors, such as job scheduling, control of raw materials usage and inter-personal conflicts between the key players, also need to be addressed if a satisfactory outcome is to be achieved.

\section{Roadmaster Roading Contractors Case}

The following material are provided to students: 


\section{Memo to the student "Software Unlimited consultants" from their boss ${ }^{1 !}$}

A couple of weekends ago, I spent some time with Monty Hedley, an old friend of mine, who's the Managing Director of Roadmaster Roading Contractors. I've now received the attached letter from him. He's looking for help in analyzing some problems that have arisen in his firm. I think this might be a good problem for you to work on as junior analysts - it's small enough for you to handle, but has sufficient complexity to extend you. I'd like you to meet with some of Monty's staff to explore their situation.

From what Monty has told me, there's not likely to be an easy solution. In fact, I'm not sure how clear Roadmaster is about what its problems really are. I don't know how much you can find out from one interview with the staff, so I don't expect you to come up with a complete solution straight away. But I do hope you can develop an initial assessment of the situation, and see if there's an opportunity for us to do business with Roadmaster.

When you meet with Monty's staff, try to find out what kind of help they'd like from us, and what we can offer them. This will be a 'free' session, part of developing potential business for us with this firm. After you have met, prepare a recommendation for me on what, if anything, we can do. I'd also like you to prepare a presentation for the Roadmaster staff on the results of your investigation.

Monty has been in business thirty years or more, and he's a pretty astute person, so you'll have to develop a clear proposal and figure out what key points are necessary to sell our services. This should be a good opportunity for you to show me that you can generate new business for our company.

Jane Brown

\section{Letter from Monty Hedley}

Jane Brown

Director Business Systems

Software Unlimited

HAMILTON

Dear Jane,

It was good to see you again last weekend. I hope you're happy with your driveway, now that we've got the water tables and culverts sorted out.

Thank you for taking the time to discuss our problems with this new Council roading contract. I'd like to take up your offer of an initial meeting with your consultants to get an objective perspective on the issues.

Let me go over the situation again. Our Contracting Division has traditionally done civil projects for local councils, and roading, drainage and farm site development work for local farmers. These are all one-off projects, where we go in, do the job and finish. We know what we're doing and we do it well. However we recently won a three-year on-going road maintenance contract with Waitomo Town Council, and that requires a totally different approach. It's a big contract, worth three million dollars over the three years, and so far it just hasn't gone smoothly. We started off just managing it like any other contract, but that hasn't seemed to work. There are a number of problems:

- We're getting complaints from the Council that urgent jobs aren't being done in time, and that job quality is not up to scratch. We have a contract supervisor, Ben Jackson, whose sole responsibility is this contract. He liaises with the Council on what work has to be done and schedules the men and machines accordingly. He says it's all the Council's fault, because they mark everything urgent, but I'm not sure about that.

\footnotetext{
${ }^{1}$ The format of the memo and the client's letter is based on a similar format used in the case study outline in Hoffer, J. A., George, J. F. \& Valacich, J. S. (1996) Instructor's Manual: Modern Systems Analysis and Design. Menlo Park, CA: Benjamin/Cummings.
} 
- We've had problems with the Council rejecting the amount we claim each month. Sometimes the amount they refuse to pay is substantial, thousands of dollars. It seems like there's disagreement about what work has been done, but I don't know why this should be happening, because we have procedures in place to request inspection of completed work.

- We're also losing money on the contract, and this is serious. We thought we'd done the quotation pretty well - George Small (our Contracts Manager) has never slipped up before, and we're not sure what the problem is. At first we thought it was just because of the disputes over payment of the claim, but I have a gut feeling that there's more to it than that.

I've asked George to take a closer look into the running of this contract, but I'm worried that he's not up to speed with the computer systems that Ben is using, and that may be part of the problem. Even though I'm not sure that a new computer system will solve everything, it might help to have some insights from the experts in that area.

Unfortunately, I can't meet with your consultants myself, as I will be in Australia to inspect some new roading equipment that we badly need. However, I'll arrange for you to meet with George and Ben, and our Office Manager, Mary Goddard. George has full authority from me to take any steps necessary to deal with this situation and I should be back from Australia in time to discuss any proposal your consultants wish to present.

Kind Regards,

Monty Hedley

Managing Director - Roadmaster Ltd.

\section{Case details given to role-play staff}

The following extra case details are provided to staff involved in the role-plays. Students do not receive this information.

\section{The Firm}

Roadmaster Ltd. is a road construction contracting firm located in the central North Island of New Zealand. The company's work includes major one-off road construction projects on a quotation basis for local councils, and small track and drainage jobs for local farmers. With a staff of over 60 Roadmaster is a significant employer of local labor. Roadmaster's fleet comprises over 120 vehicles, including a large number of earthmoving and construction machines. Some of these machines are only used for very specialized work, and are therefore idle for much of the time. Roadmaster must achieve a return on its considerable investment in equipment by competing successfully against other contractors for a wide variety of contracting work.

The company is split into three divisions, Contracts, Quarries and Fleet Service, and has a small administration department. The Contracts Division is responsible for major contract work for local councils, for minor quoted work for farm customers (including drainage, road and site development) and for sundry jobs such as road gravel delivery. The Quarries Division runs a centrally located quarry producing over 100,000 tons of gravel per year, most of which is used in the Contracts operations although some is sold directly to farm customers. The Fleet Services Division operates from the workshop at the company headquarters and maintains all vehicles, including trucks and utility vans and earth-working machinery such as graders, bulldozers, diggers and rollers.

\section{The Information Systems}

Historically, the Contracts Division's performance has been determined by analyzing the performance of the individual trucks and machines in the fleet. A Vehicle Ledger captures the costs incurred (including labor) and revenue earned by each vehicle. This information has been summarized for the profit and loss report for the Division. This primary analysis view by vehicle has evolved from Roadmaster's beginnings as a supplier of labor and machinery on hourly rates, when it was important to know whether a particular vehicle was paying its way.

More recently Roadmaster has diversified into undertaking larger contracts on a quotation basis, supplying all machinery and quarry materials to complete the whole job. This has created a contention for information between the vehicle and the contract, with managers now needing information about individual contract performance as well as the performance of individual vehicles.

The current computing system, which batch processes payroll, vehicle, creditors' and debtors' transactions, is a standard accounting package that has been customized to meet the individual vehicle reporting requirements. Unfortunately, this computing system is an 'orphan'. The customizations have made the programs incompatible with new releases of the package so no upgrades have been performed for several years. The software is now substantially different from the latest standard version of the package and the supplier will no longer support it. Roadmaster's version is so different from the latest version that the only practical upgrade option is to abandon the existing package and install the new one. However while the new version of the package meets Roadmaster's new contract based reporting requirements, it does not retain the individual vehicle 
reporting options. Roadmaster's disenchantment with the supplier's 'take it or leave it' attitude has created an impasse. Roadmaster struggles on with the existing package and the administration staff rely on ad hoc spreadsheets and manual ledgers to prepare the contract analysis reports.

\section{New Ventures}

Roadmaster has now branched into a new area, with an ongoing 3-year road maintenance contract for a local town council, (Waitomo Town Council). This contract is an innovation for Roadmaster since it involves on-going maintenance of existing roads rather than one-off construction of new roads. The contract is much larger than anything Roadmaster has tackled in the past and has required substantial extra investment in plant and machinery. A maintenance contract also requires different management skills both in the areas of supervision of the field staff and in contract administration.

Roadmaster has realized there are three particular areas of concern for the new contract. Firstly, the day-to-day control of field staff is proving problematic. Traditionally, Roadmaster assigned the required staff and machines to a oneoff contract and kept them there until the job was finished. However with the maintenance contract, they receive a number of job requests each day for different types of work, in different geographic locations, and with different required response times. This requires new management skills in terms of planning and scheduling work to ensure the most efficient use of staff and machinery, while at the same time avoiding any penalties for failing to meet the required response times.

This scheduling problem is made worse by the way work is assigned and contract payments are approved. On one-off contracts all the work is assigned at the start and Roadmaster submits a monthly progress claim based on the percentage completion of the total contract. This claim is processed and approved by the client and Roadmaster receives monthly payments to offset costs incurred on the contract to date. On the new maintenance contract the Council assigns work on daily work orders each comprising one or more jobs. The Council will only accept monthly claims for fully completed work orders. Therefore Roadmaster has to plan and schedule work to avoid large numbers of inprogress jobs at the end of a month because Roadmaster must carry all costs incurred on incomplete work orders through the following month. The carry-over of in-progress jobs each month is causing severe pressure on Roadmaster's cash flow, which has already been put under stress by the start-up costs associated with the new maintenance contract.

The second area of concern is the monitoring of job performance. Roadmaster has found that the first few months of this contract have not been as profitable as expected.
Currently, the administration staff uses ad hoc spreadsheets to report costs at the contract level only. Managers can only identify actual costs of labor, machinery and materials on an individual job basis by manual review of the original job sheets. Thus, it is difficult for managers to identify exactly where higher than expected expenses are occurring. In particular, there is currently no method of accurately measuring the quantity of raw materials used for each job. Roadmaster knows the total amount of raw material used on the Waitomo Town Council contract but relies on the supervisor's visual estimates to ensure the correct amount is used for a particular job.

Finally, Waitomo Town Council requires Roadmaster to produce an itemized claim each month. This claim must provide, for each item on the contract, full details of all jobs within that item completed for the month. Once again the current system can only produce summary reports and this is insufficient for the Council's itemized claim process.

\section{The People}

As with most organizations, the problems within Roadmaster are not necessarily solved simply by the provision of better information systems. The various key people in the organization are also critical to the success or failure of any proposed intervention. The key players in this case are George Small, Contracts Division Manager, Ben Jackson, Waitomo Town Council Contract Supervisor, and Mary Goddard, Office Manager.

George Small. George has been with Roadmaster since Monty Hedley first started the firm thirty years ago. George's many years of practical experience with road construction are highly valued by Monty who has promoted him to his present position of Contracts Manager. However George is more at home out on the site than dealing with the paperwork. George's ability to quote accurately and competitively on the one-off roading contracts is legendary within the firm. Although no one else can understand how he reaches the final figures (he literally scribbles his calculations on the back of an envelope) his quotations are regularly successful, and his tight on-the job supervision of the ensuing contracts ensures a profitable outcome. He is able to monitor progress on these one-off contracts by comparing the monthly progress payments received against the total labor and machinery costs incurred to date.

George was closely involved in the original quotations for the Waitomo Town Council contract but he and Monty agreed that this contract was too large for George to manage alongside his other duties. So they appointed a full-time contract supervisor Ben Jackson to supervise the day-today work and to prepare the Council's detailed reporting requirements. Ben reports directly to George but George has a 'hands-off' approach to staff supervision and Ben has 
developed his own approach to the management of the contract.

Now problems with the Waitomo Town Council contract supervision are beginning to surface and Monty has asked George to focus entirely on this new contract and get it running smoothly. George recognizes there are problems with the on-site supervision and is trying to get Ben on track with that. However he has realized that one of the major problems with Ben's supervision is that he is simply not spending enough time on site. Ben argues that he has to spend a large part of his time dealing with routine administration of the contract, and George is out of his depth here. George has always left administration matters to Mary, the Office Manager. While there have been frequent battles between George and Mary over her insistence on the need for complete and accurate records, and his more laissezfaire approach, he does have respect for her ability to keep track of the business costs. However in a fit of pique at the start of the contract, George conducted a quiet campaign with Monty against the suggestion that Mary's hours should be increased to enable her to handle the Waitomo Town Council work. George argued that if Ben was full-time on only one contract he should have more than enough time to handle all aspects of the work and so extending Mary's hours would be unnecessary. George now regrets that argument, but Monty is holding George to his claim that a full-time contract supervisor should be able to cover everything.

George has realized that keeping track of detailed costs for this contract is a major concern. The Council's payments are made per job on the daily work orders, while Mary's reports can only track the total labor and machinery costs over the whole contract. This means that George has no way of identifying which jobs are being done at a loss.

George is very concerned about his inability to understand the spreadsheet systems Ben has set up to track the jobs and produce the required reports for the Council. George's instinctive reaction is to get Mary to sort it out but given his earlier opposition to Mary's involvement he doesn't want to back down now. Neither does he want to lose face with Ben by admitting he doesn't understand what's going on.

Mary Goddard. Mary has been Office Manager at Roadmaster for over 12 years. She has seen the firm grow substantially in that time and takes pride in the systems she has set up. The computing system cannot provide the contract reporting required by Roadmaster so Mary spends much of her time accumulating figures in manual ledgers to keep track of costs on the various contracts. This is timeconsuming and Mary is often late with the reports.

Mary and George have a grudging respect for one another but that doesn't prevent them from continually sparring over the accuracy of the records. Mary is always arguing that George doesn't appreciate the importance of accurate record keeping on the job. George responds that Mary's reports are always too late to be of any use to him.

Mary has been concerned from the start (rightly) that Ben didn't have enough knowledge and experience to set up the appropriate systems. She has tried surreptitiously to keep an eye on what he's done and is very concerned about the spreadsheets he has set up. She is upset that she wasn't involved in setting up these spreadsheets, but she only works 30 hours a week and Monty refused to extend her hours in order to set up systems for recording the Waitomo Town Council information. She's now very determined not to get involved until she wrings an admission from Monty and George that she's needed and that they're prepared to back that up with an increase in her hours and pay.

Ben Jackson. Ben is young, ambitious, and very brash. He's climbed the ladder with some basic training from the Maniatoto District Council in the southern part of New Zealand and tends to be a 'hotshot' type. The Waitomo Town Council contract supervisor's job was a big jump for Ben and he's out of his depth. In his previous job he had worked under the close supervision of a senior engineer who had provided a lot of guidance, both in personnel management and in the development of suitable record keeping procedures. Ben exaggerated his ability and experience in both these areas at his job interview and is now struggling to meet the expectations he created.

Ben's knowledge of computers is largely self-taught so his spreadsheet methods are unorthodox. He is very defensive if Mary questions him about the spreadsheets he uses to track the Council jobs partly because he's afraid she'll discover something he's overlooked and partly because he fears he'll lose his job if Mary reports that his systems are inadequate. He never documents his spreadsheets so it's difficult for anyone else to see how they work, especially as he takes delight in setting up complex links and playing around with macros, etc. However most of the time what he actually does is cut and paste from one sheet to another. He has on occasion 'lost' data doing this and ended up redoing hours of work.

Ben is a little resentful that Monty has asked George to be more directly involved in the Council contract. He believes he has been doing a good job, so he isn't making much effort to assist George in sorting out the problems that are occurring. Ben sees the attitude of the Council staff as the major problem. He believes the Council staff is resentful and obstructive because the Council's own roading team was disbanded when the road maintenance contract was awarded to Roadmaster. There are some areas where the Council has been difficult, particularly in the way they allocate jobs over a wide geographic range every day and this is enough for Ben to use the Council as a scapegoat whenever something goes wrong. 


\section{Teaching Notes}

\section{Teaching Aims}

It is commonly accepted that requirements analysis plays a critical role in determining the success of system implementation. Faulty requirements analysis has been identified by a number of authors as a leading cause of information system problems and failures (Brooks, 1987; Hoffer, George \& Valacich, 1996; Laudon \& Laudon, 1996). Yet, textbooks used in tertiary institutions to teach systems development methods tend to present information requirements analysis as a simple and straightforward process of interviewing users and specifying their needs (Hoffer, George \& Valacich, 1996; Whitten, Bentley \& Barlow, 1994). Interviewing and communication skills are presented as an essential part of an analyst's repertoire, but there is rarely much attention paid to the practical difficulties of initial investigation of problem situations. Two areas are of particular concern. First, it is important to develop in students an appreciation of the wider organizational issues that can impact on what appears on the surface to be a straightforward information system problem. Second, it is important that students learn practical skills to help in investigating the complex and confused problem situations they are likely to face in the 'real world'. Just lecturing about information systems in their organizational context, for example, or about interviewing and analysis skills does not of itself ensure that the students will appreciate the contextual issues in practice, or understand how to use appropriate interview techniques in real situations. Research in training methods (Burke \& Day, 1986) suggests that skillsbased training is most effective if students have had an opportunity to apply the skills in a realistic situation and to receive feedback.

This case is one of a set of four cases intended to give students practical experience in the investigation of an initial problem situation. The teaching aims are to:

- give students the opportunity to practice and apply skills in investigating and developing initial systems requirements;

- develop an appreciation in students that information systems solutions must take into account the organizational and social context of the work environment in order to lead to successful system outcomes; and

- give students an insight into the special problems facing small firms regarding information management.

The cases follow lectures on information systems in their organizational context, information gathering and analysis skills, and aspects of systems development methodologies particularly relevant to the information gathering stages of system development. Students review different techniques for analyzing and evaluating information gained from interviews, including critical factor analysis, problem and opportunity analysis, traditional methodologies such as Information Engineering and SSADM, and Soft Systems Methodology, (see, for example, Avison \& Fitzgerald, 1995, for coverage of these). The students are encouraged to explore the application of these techniques in the case studies.

\section{Preparation}

Students work in teams, playing the part of new employees of a software-consulting firm on their first major assignment. Each team is assigned to a different case and those not involved in a particular case observe the interviews and participate in the feedback sessions after the interviews. Students get only a memo from their boss and a letter from their client.

Students are expected to carry out their investigation with minimal guidance from the instructor. They are required to conduct the role-play interviews in a fully professional manner, to develop a report analyzing the situation for their boss, and to prepare a presentation for the clients. Student approaches to the exercise have varied considerably, but generally the more successful students make considerable effort to inform themselves about their clients' area of business, and to plan and prepare their interviews, and analyze and organize their findings.

I have found it helpful to have a meeting of the Roadmaster role-players before the interviews, so that we can go over the case and our characters and agree on our 'story'. The role-players are encouraged to develop 'difficult' aspects of their characters (for example, taciturnity, vagueness, being in a hurry, etc.) so that the students experience the challenge of handling different interview situations. The teaching colleagues who assist with the role-plays need to commit about two to three hours of their time - about an hour for preparation, half an hour for the interview, and an hour for the final presentation and debriefing session. In practice, the role-plays of the interviews have followed quite different tracks with different student groups depending on the students' focus. This has sometimes required the roleplayers to improvise if the students ask detailed questions about areas not fully elaborated in the notes. Sometimes confusing or contradictory answers have been given but this reflects what frequently happens in real life, particularly as different interviewees have different perspectives on the situation, and the answers tend to reflect the different priorities of each of the key players. Colleagues who have assisted with these role-plays have commented on how enjoyable they are, and so far have always been willing to return for a repeat performance.

It should be noted that this approach to case teaching requires considerable time commitment from teaching colleagues, and this is a limitation for larger class sizes. Currently, it has been used in a tutorial situation with class 
sizes of no more than twenty students, and a maximum of five students working on each case. Given that one of the aims of this approach is to develop students' practical skills in 'real-life' interview situations, participation in the roleplay interviews is an important component of students' overall skill development. It is possible with larger classes to have students observe volunteers do the interviewing and then develop their proposals in small groups. However this approach loses the actual practice element that is central to this skills-based training approach.

\section{Debriefing}

An initial debriefing of the interview takes place in the next class meeting. Students participate in a group discussion on the conduct of the interviews. As well as discussing how well student interviewers planned and structured their interviews, we also discuss how they handled the personalities and dealt with any sensitive issues and review various approaches for dealing with the interview situations they faced.

The final debriefing takes place once the students have made their presentation to the clients. The colleagues involved in the role-play are present and provide feedback to the student teams on how well their presentation addresses the client's concerns. At this session discussion focuses on the various issues that arose during the interviews, with particular emphasis on the wider problems that could impact any proposed information system solution. Discussion of these issues (management, political, inter-personal) is encouraged in order to give the students a better appreciation and understanding of the need to consider the whole context of the organization in making their recommendations. We also review the techniques the students used to analyze and present their information (critical factor analysis, Soft Systems techniques, etc.) and discuss how useful these were in practice, and which were most appropriate for the situation. This review leads into discussion about the theory of methodologies in general and how practical their application is in real-life situations, particularly in the small business context.

Finally, in the debriefing session we discuss the specific issues and themes the students have discovered and what possible solutions might be explored.

\section{Specific issues and themes}

Information systems issues in this case fall into three main areas - control of daily job scheduling for the maintenance contract; dependence on spreadsheets for much of the major record-keeping, reporting and analysis of performance; and 'people' issues.

A very useful line of discussion can explore the most suitable information systems support that can be provided for the job scheduling issues. Students tend to want to rush in and 'build a system' and discussion can focus on whether this is indeed the best and most cost-effective solution in this situation. The firm actually opted for a manual and highly visual whiteboard system, plus some basic training for Ben, which resulted in a dramatic improvement in the control of daily job scheduling at very little cost.

The reliance on poorly planned and documented spreadsheets is typical of many companies of this size (Cragg \& King, 1993). Astute students will have discovered from their interviews the vulnerability of Roadmaster's critical management accounting information, which is contained in undocumented spreadsheets prepared and maintained by inexperienced or self-taught staff. They will also have uncovered that much of Mary's 30 hours per week is eaten up in 're-jigging' information already captured in the existing information system, in order to present the kind of information that management requires on the one-off contracts. Similarly, Ben re-enters and re-analyzes data to keep track of his daily work orders and to prepare the monthly claims for the Council. This is obviously an area with potential for computerized solutions. Once again, however, students tend to rush in with a proposal to build a database and it is useful to encourage them to fully investigate what 'buy' options exist. The firm's final choice was to purchase a packaged solution with some limited customization provided by the vendor.

The people issues are well worth following up in discussion. The role players are encouraged to highlight the tensions between Ben and Mary, and Mary and George during their interviews, and George shows considerable discomfort about anything related to "them computer thingies"! Students are able to identify that the lack of co-operation and communication between Mary and Ben, and George's computer phobia, are major hurdles to be overcome if any system implementation is to be successful. Some students will also recognize that little has been done to encourage a useful dialogue with the Waitomo Town Council and that some problems need to be resolved here too. In fact the most significant system improvements in the real situation came when George initiated better liaison with the Council over allocation of jobs and streamlining of reporting requirements. The company also ran team-building exercises for the main staff involved in the Council contract, and encouraged George to take some basic computer training so that he could appreciate what information he could get from the new system.

\section{Conclusion}

There are a number of practical results from using this case study. Students experience a real-life requirements analysis situation and have the opportunity to become more proficient in investigating and developing initial requirements in a 'safe' setting. Our experience has been that students de- 
velop a better understanding of the need to take into account the context of the organization and the interactions of the people in it when making recommendations to deal with problem situations identified. They also have the opportunity to develop teamwork skills and to practice professional presentation and report writing skills. However in addition to these very practical outcomes, the students gain a clearer understanding of the various systems development methodologies, tools and techniques that they have reviewed in theory, and their application and limitations in practice.

\section{References}

Avison, D. E. and G. Fitzgerald (1995). 'Information Systems Deve- $\bar{L}$

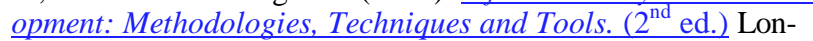

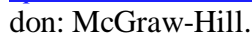

Brooks, F. P. Jr. (1987). No silver bullet: Essence and accidents of software engineering, IEEE Computer, 20(4), 10-19.
Burke, M. J. and R. R. Day (1986). A cumulative study of the effectiveness of managerial training, Journal of Applied Psychology, $71,232-245$

Cragg, P. B. and M. King (1993). Spreadsheet modeling abuse: An opportunity for OR? Journal of the Operational Research Society, 44(8), 743-752.

Hoffer, J. A., J. F. George, and J. S. Valacich, (1996).Modern Syst Tems Analysis and Design.'Menlo Park, CA: Benjamin/Cummings.

Laudon, K. C. and J. P. Laudon (1996) Management information

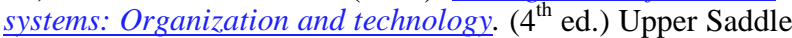
Riveré, NJ:"Prentice- Hall.

Whitten, J. L., L. D. Bentley and V. M. Barlow (1994) $\bar{S}$ stems

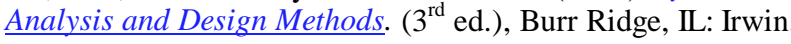

